\title{
Assessment of Breast Feeding Practice and Risk Factors Associated with Severe Acute Malnutrition among Children Admitted to Addis Ababa Governmental Hospitals, Ethiopia, 2014: A Cross-Sectional Facility Based Study
}

\author{
Gebre Gelana ${ }^{1}$, Berhanu Dessalegn ${ }^{2}$, and Girma Alemu ${ }^{3}$ \\ ${ }^{1}$ Department of Nursing, Arba Minch University, Arba Minch, South West Ethiopia \\ ${ }^{2}$ Department of Nursing and Midwifery, Tikur Anbesa Specialized Hospital, Addis Ababa University, \\ Addis Ababa, Ethiopia \\ ${ }^{3}$ GA: MSc Candidate at Pan Africa University of Life and Earth Science Institute, Ibadan, Nigeria
}

\section{Corresponding Author}

Gebre Gelana

ggelana27@gmail.com

\section{Editor}

Sigrid Mennickent

\section{Dates}

Received 19 April 2016

Accepted 27 October 2016

Copyright (C) 2017 Gebre Gelana et al. This is an open access article distributed under the Creative Commons Attribution License, which permits unrestricted use, distribution, and reproduction in any medium, provided the original work is properly cited.

\begin{abstract}
Background: Malnutrition remains one of the most common causes of morbidity and mortality among children throughout the world. It is responsible for over $50 \%$ death of under age of 5 years children. Objective: To assess feeding practice and factors associated with severe acute malnutrition in under age of 5 year children admitted to Addis Ababa Government Hospitals, Ethiopia, 2014. Methods and Materials: A cross sectional study design was conducted on 151 under age of 5 year children admitted to Addis Ababa Governmental Hospitals from April to May 2014. The required number of sample was selected based on the registration and diagnosis. Data was collected by review of medical records and interview of the family member nearby during data collection. The data was manipulated and analyzed by using Epi.info version 3.5.4 for windows and SPSS version 16.0. Results: Out of one hundred fifty one study subjects, $124(82.1 \%)$ of them breastfed; but majority of them, $65.4 \%$ did not practice exclusive breast feeding. Maternal illiteracy had 2.46 times high risk and significant association with severe acute malnutrition $(\mathrm{AOR}=2.46,95 \% \mathrm{CI}, 1.4-42.4)$. Being age younger than 11 months also showed 5.97 times high risk and statistically significant association with severe acute malnutrition (AOR $=5.97,95 \% \mathrm{CI}, 1.8-20$ ). Children of governmental employee mother were 2.29 times high risk to be affected by marasmus (AOR $=2.29,95 \% \mathrm{CI}, 1.4-3.86$ ). Male children were 2.28 times higher risk to be affected by the case than female children (AOR $=2.28,95 \% \mathrm{CI}, 1.1-4.9$ ). Conclusion: Maternal illiteracy, maternal occupation, sex of the child being male and age of the child younger than 11 months have strong and statistically significant association with child severe acute malnutrition.
\end{abstract}

Keywords: Risk factors, severe acute malnutrition, Children, Hospitals. 


\section{Background}

Poverty and ignorance play important roles at the background in the causation of malnutrition especially in the developing world. Poor feeding practices have been identified in the developing world to arise from ignorance about adequate breastfeeding and appropriate weaning practices. All these are closely related to the socioeconomic status and sizes of families [1].

In low and middle income countries (LMIC), an estimated 6.9 million children under the age of five still die annually because of preventable and treatable illnesses including pneumonia, diarrheal disease, malaria, and underlying malnutrition. In developing countries, malnutrition is a contributing factor in over $50 \%$ of child deaths [3].

Malnutrition affects one out of every three preschool age children living in developing countries. In South Asia, increases in women's status have a strong influence on both the long- and short-term nutritional status of children, leading to reductions in both stunting and wasting. In Sub-Saharan Africa too, women's status and the long- and short-term nutritional status of children are linked [4].

According to the study conducted in Zaria city, Northwest Nigeria, the mean prevalence of underweight malnutrition, was found to be $67 \%$. In addition, this study has established that maternal literacy affects the nutritional status of children; as children of illiterate mothers (with no formal education) have increased risk for development of malnutrition in children under the age of 5 years especially for stunting [5].

Parental illiteracy is found to be associated with a higher risk of severe acute malnutrition (SAM). This is observed in studies done in North Wollo, Ethiopia [6], and in other African [7, 8], Southeast Asian [9, 10] and Latin American countries [11]. In a case-control study in Bangladesh, the maternal illiteracy was associated with a fourfold increase in the risk of SAM in their children [12].

Many studies show other factors contribute to acute child malnutrition. Studies done in Nigeria, India, a community based study done in Jimma and a case control done in Gonder University, Ethiopia showed that children with malnutrition lived in a household with low monthly income [13-15].

According to nutrition baseline survey report for the national nutrition program of Ethiopia , $12 \%$ of children aged 6 to 59 months were wasted and three percent of them were severely wasted, this problem also hold back progress towards reaching MDG 4 to reduce child mortality [16]. In which The primary impact objectives include reduce the prevalence of underweight from $38 \%$ to $30 \%$; Reduce the prevalence of stunting from $46 \%$ to $40 \%$ and reduce the prevalence of wasting from $11 \%$ to $5 \%$ by 2013 [17].

From Ethiopian Demographic and Health survey (EDHS) 2011, the mother's level of education generally has an inverse relationship with stunting levels. For example, children of mothers with more than secondary education are the least likely to be stunted $19 \%$, while children whose mothers have no education are the most likely to be stunted 47\% [18].

A larger family size is associated with an increased risk of SAM. The effect of a large family size with overcrowding and inadequate spacing has been implicated as a risk factor for severe malnutrition in different studies as well $[19,20]$. In hospital based prospective study conducted 
in Sukkur, large family size is highly associated with an increased risk of SAM. It was seen that $66.6 \%$ cases were from large family size [21].

The risk of SAM is increased when the monthly income is lower than 50 US Dollar. Similarly poor family income has been found as a risk factor for severe acute malnutrition in studies done in Nigeria [20], and India [9]. A community based study done in Jimma, Ethiopia showed that children with malnutrition lived in a household with low monthly income [13].

As a global public health recommendation, infants should be exclusively breastfeed for the first 6 months of life to achieve optimal growth, development and health. Thereafter to meet their evolving nutritional requirements, infants should receive nutritionally adequate and safe complementary foods while breastfeeding continues for up to two years of age or beyond [22]. Introduction of other diet before six months of age is 3.2 times more common with cases than in the controls; and initiation of complementary diet after one year of age was 3.4 times more common in the malnourished group, indicating that children with severe acute malnutrition are started with complementary diet either too early or too late [15].

A study done in China showed that the introduction of other diet before the age of six months increased the prevalence of pneumonia and diarrhoeal disease [23]. Similarly a study done in Kenya showed an increased risk of being underweight when complementary food was started early. The proportion of malnourished children was higher among those who were abruptly weaned $(43.7 \%)$ than gradually weaned (23.3\%) children [24].

\section{Materials and Methods}

\subsection{Study setting and design}

A facility based cross-sectional study was conducted in Addis Ababa Governmental Hospitals to assess risk factors associated with SAM among children admitted to Hospitals from April to May 2014. According to Addis Ababa Health Bureau Report of 2010, there are 49 hospitals of which 12 are government owned, 5 NGOs and 32 are private, 27 public health centers, and 130 public health stations, 700 different levels private clinics are found in Addis Ababa city Administrative Region.

\subsubsection{Sample size determination and sampling technique}

The required sample size was calculated by the following formula and p-value, prevalence of wasting from Ethiopian Demographic Health Survey 2011, 10\% [25].

A single population proportion formula, $\left[n=(Z \alpha / 2)^{2} p(1-p) / d^{2}\right]$, was used to estimate the sample size. Assuming marginal error 5\% $(d=0.05)(p=0.1), 95 \%$ confidence interval. Computing with the above formula and $10 \%$ of contingency for non respondent rate gives a total sample size of 151 .

All children admitted to hospital with severe acute malnutrition before and during data collection were included as study participant based on their registration documented in registration book. Unfortunately if their registration book is incomplete or not met the inclusion criteria, the child was automatically excluded. 
The hospitals were selected based on the service they provide. Based on this the public hospitals which provide therapies for malnutrition inpatient are Black Lion Hospital, Zewuditu Memorial Hospital, Yekatit 12 Hospital and St. Paul Hospital Millennium Medical College. Black Lion Hospital was excluded to prevent sample overlap because most of the cases were taken as referral from other hospitals.

The children fulfilling the criteria were included from the selected hospitals until the required sample size saturated. Samples were selected consecutively starting from April to May 2014 using Patient's registration book.

\subsubsection{Data collection and quality control}

The structured questionnaire was translated to Amharic languages and the questionnaire was pretested on 15 children admitted with SAM to Black Lion Hospital. Training was given for one supervisor (Bachelor Nurse) and four data collectors (Diploma Nurses). The data was collected by reviewing records from inpatient registration book, and then interview of family member nearby.

The data collection format of each data collectors was checked daily for completeness, missed or other relevant information on meeting and close supervision during data collection. Data editing was done by the data collectors, supervisors and the principal investigator in the field and further cleaning of data, coding and entry to computer.

\subsection{Statistical analysis}

Data was entered to Epi-Info 3.5.4 for windows and analyzed using SPSS version 16.0 for windows. The data was cleaned and edited before analysis. Data exploration was undertaken to see if there were odd codes or items that were not logical and then subsequent editing was made. Frequency distributions, pie chart, figures and tables were used to provide an overall and coherent presentation and description of the data. Binary logestic regression and multiple logestic regression tests were used to express the magnitude and association between independent variables and severe acute malnutrition.

\subsection{Ethical consideration}

The thesis proposal was submitted to Department of Nursing and Midwifery, School of post graduate studies of Addis Ababa University Nursing Research Review Committee for approval. Followed the approval by Institutional Review Board, Official letter of co-operation was written to the concerned bodies by School of Allied Health sciences, Department of Nursing and Midwifery. As the study was conducted through review of medical records and non invasive data collection methods, the individual patients were not subjected to any harm as far as the confidentiality was kept. No personal identifiers were used on data collection form. The recorded data was not accessed by a third person except the principal investigator, and was kept confidentially. 


\section{Results}

\subsection{Description of socio demographic of the family and the child}

The total sample size included in the study was 151 subjects. All the study subjects provided their relevant information which making the response rate $100 \%$. The mean age of the mother's is 27.99 ( \pm 4.76 ). Concerning educational status of the mother's $37.7 \%$ was educated to grade $1-8$, and $17.2 \%$ have no formal education. Forty three percent of mothers were daily labor workers. Regarding the ethnicity, 30.5\% were Oromo, 29.8\% were Amhara and $17.2 \%$ were Tigre. Concerning religion, $63.6 \%$ were Orthodox, $18.5 \%$ were Protestant and the $17.9 \%$ were Muslims (Table 1).

Table 1: Socio demographic characteristics of the family and the child of the children admitted with SAM to AA Governmental Hospitals, 2014.

\begin{tabular}{|c|c|c|c|}
\hline & Characteristics & Frequency & Percent \\
\hline \multirow[t]{4}{*}{ Age of mothers } & $20-24$ & 31 & 20.5 \\
\hline & $25-29$ & 69 & 45.7 \\
\hline & $30+$ & 51 & 33.8 \\
\hline & Total & 151 & 100.0 \\
\hline \multirow[t]{6}{*}{ Ethnic Group } & Amhara & 45 & 29.8 \\
\hline & Oromo & 46 & 30.5 \\
\hline & Tigre & 26 & 17.2 \\
\hline & Gurage & 25 & 16.6 \\
\hline & Others & 9 & 6.0 \\
\hline & Total & 151 & 100.0 \\
\hline \multirow[t]{4}{*}{ Religion } & Orthodox & 96 & 63.6 \\
\hline & Protestant & 28 & 18.5 \\
\hline & Muslim & 27 & 17.9 \\
\hline & Total & 151 & 100.0 \\
\hline \multirow[t]{6}{*}{ Mother's educational status } & Illiterate & 26 & 17.2 \\
\hline & Can read and write & 29 & 19.2 \\
\hline & Grade $1-8$ & 57 & 37.7 \\
\hline & Grade $9-12$ & 28 & 18.5 \\
\hline & College/University & 11 & 7.3 \\
\hline & Total & 151 & 100.0 \\
\hline \multirow[t]{6}{*}{ Mother's Occupation } & House wife & 48 & 31.8 \\
\hline & Government employee & 9 & 6.0 \\
\hline & Merchant & 21 & 13.9 \\
\hline & Daily labor & 65 & 43.0 \\
\hline & Private worker & 8 & 5.3 \\
\hline & Total & 151 & 100.0 \\
\hline \multirow[t]{5}{*}{ Marital status } & Single & 4 & 2.6 \\
\hline & Married & 122 & 80.8 \\
\hline & Divorced & 22 & 14.6 \\
\hline & Widowed & 3 & 2.0 \\
\hline & Total & 151 & 100.0 \\
\hline
\end{tabular}




\begin{tabular}{|c|c|c|c|}
\hline & Characteristics & Frequency & Percent \\
\hline \multirow[t]{6}{*}{ Fathers Educational status } & Illiterate & 7 & 5.7 \\
\hline & Can read and write & 10 & 8.2 \\
\hline & Grade $1-8$ & 53 & 43.4 \\
\hline & Grade 9-12 & 31 & 25.4 \\
\hline & College/University & 21 & 17.2 \\
\hline & Total & 122 & 100.0 \\
\hline \multirow[t]{5}{*}{ Father's Occupation } & Government employee & 16 & 13.1 \\
\hline & Merchant & 26 & 21.3 \\
\hline & Daily labor & 60 & 49.2 \\
\hline & Private worker & 20 & 16.4 \\
\hline & Total & 122 & 100.0 \\
\hline \multirow[t]{6}{*}{ Monthly income } & $<500$ Birr & 29 & 19.2 \\
\hline & 500-1000 Birr & 59 & 39.1 \\
\hline & 1100-1500 Birr & 20 & 13.2 \\
\hline & 1600-2000 Birr & 22 & 14.6 \\
\hline & $>2000$ Birr & 21 & 13.9 \\
\hline & Total & 151 & 100.0 \\
\hline \multirow[t]{6}{*}{ Family size } & 2 & 13 & 8.6 \\
\hline & 3 & 31 & 20.5 \\
\hline & 4 & 63 & 41.7 \\
\hline & 5 & 34 & 22.5 \\
\hline & $>5$ & 10 & 6.6 \\
\hline & Total & 151 & 100.0 \\
\hline \multirow[t]{4}{*}{ Number of children 0-59 months in the family } & 1 & 134 & 88.7 \\
\hline & 2 & 14 & 9.3 \\
\hline & $>2$ & 3 & 2.0 \\
\hline & Total & 151 & 100.0 \\
\hline \multirow[t]{4}{*}{ Age in months } & $0-11$ & 73 & 48.3 \\
\hline & $12-23$ & 61 & 40.4 \\
\hline & $24-59$ & 17 & 11.3 \\
\hline & Total & 151 & 100.0 \\
\hline \multirow[t]{3}{*}{ Sex } & Male & 89 & 58.9 \\
\hline & Female & 62 & 41.1 \\
\hline & Total & 151 & 100.0 \\
\hline
\end{tabular}

\subsection{The types of malnutrition diagnosed by clinical and laboratory findings}

Out of one hundred fifty one children diagnosed with severe acute malnutrition and admitted to hospitals $64.2 \%$ were marasmic cases, $19.9 \%$ were kwashiorkor and the remaining $15.9 \%$ were mixed type of malnutrition (marasmic-kwash) (Table 2).

One of the criteria to classify an admitted child with severe acute malnutrition is bilateral edema. Out of one hundred fifty one children admitted with the case, $64.9 \%$ had no edema, 
Table 2: Degree of bilateral edema on admission and different form of SAM diagnosed among children admitted to AA governmental hospitals, 2014.

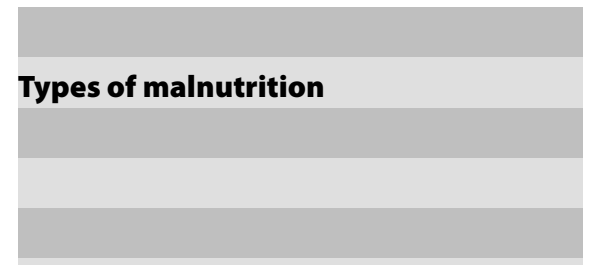

\begin{tabular}{|c|c|c|}
\hline & Frequency & Percent \\
\hline Kwashiorkor & 30 & 19.9 \\
\hline Marasmus & 97 & 64.2 \\
\hline Marasmic-Kwash & 24 & 15.9 \\
\hline Total & 151 & 100.0 \\
\hline $\mathbf{0}$ & 98 & 64.9 \\
\hline+ & 7 & 4.6 \\
\hline+++ & 27 & 17.9 \\
\hline+++ & 19 & 12.6 \\
\hline Total & 151 & 100.0 \\
\hline
\end{tabular}

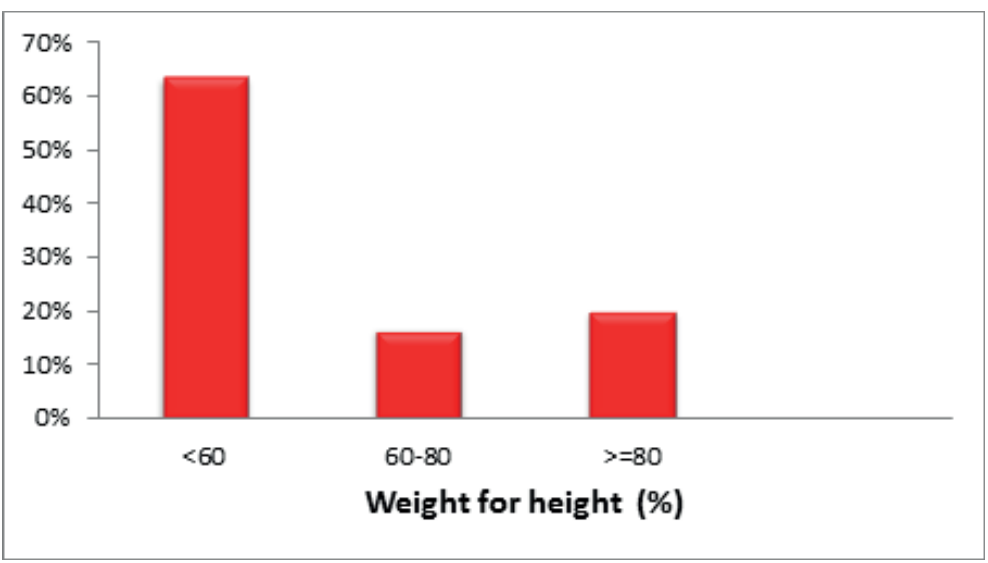

Figure 1: Weight for height status on admission of children admitted with different form of SAM to AA governmental hospitals, 2014.

$17.9 \%$ had grade II edema (++), $12.6 \%$ had grade III edema $(+++)$ and the remaining $4.6 \%$ had grade I edema $(+)$ when they admitted to the hospitals (Table 2$)$.

Regarding weight for height condition on admission, $63.6 \%$ were $<60 \%, 19.9 \%$ were $>=80 \%$ and the rest $16.6 \%$ were between $60-80 \%$. Concerning about MUAC on admission $169.5 \%$ were less than $11.5 \mathrm{~cm}$ and $30.5 \%$ were greater than or equal to $11.5 \mathrm{~cm}$ (Figure 1).

\subsection{Previous disease status of the child}

Out of one hundred fifty one study subjects, $42.4 \%$ of them reported different cases that they have experienced in a month before the study. They have reported more than one case they have experienced in the past $54.7 \%$ of them reported history of severe vomiting, $70.3 \%$ reported history of fever, $64.1 \%$ reported history of diarrhea, $26.6 \%$ reported history of pneumonia and $42.9 \%$ reported history of chronic illnesses like heart disease, Tuberculosis, and spinal cord defect (Figure 2). Concerning HIV status of the study subjects, $69.5 \%$ of them were non reactive, $29.2 \%$ were unknown result and $1.3 \%$ were reactive (Figure 3 ). 


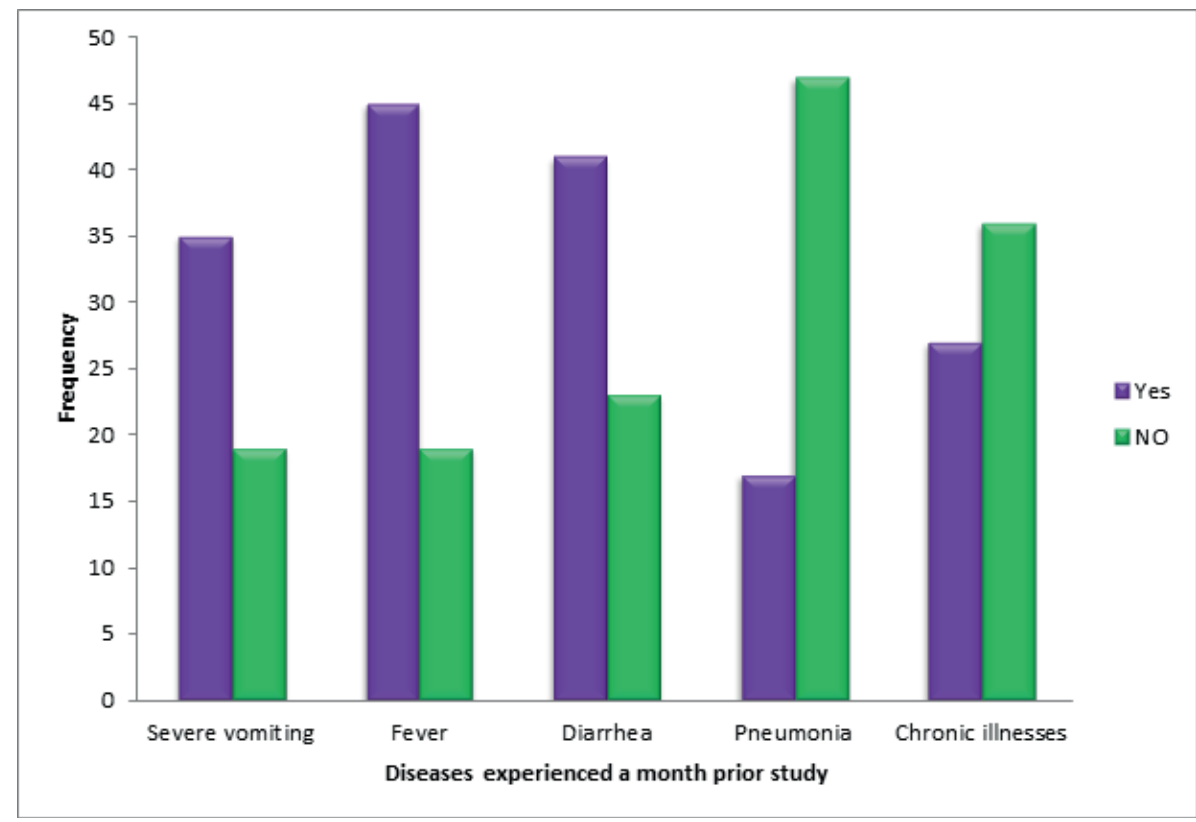

Figure 2: History of cases experienced a month prior the study by children admitted with SAM to AA governmental hospitals, 2014.

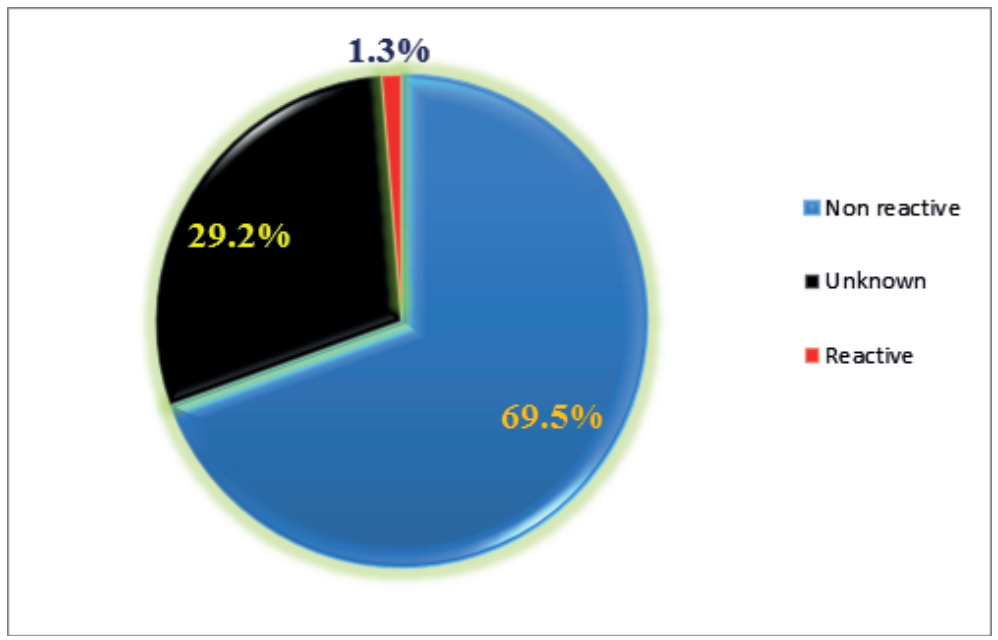

Figure 3: HIV status of children admitted with SAM to AA governmental hospitals, 2014.

\subsection{Feeding practice of the child}

Regarding breast feeding practice, most of the study subjects have fed breast milk since their birth which accounts $82.1 \%$ and the remaining $17.9 \%$ did not feed breast milk instead they have fed formula milk. Those children who have got breast milk, fed for vary duration in time. Sixty two percent $(62.1 \%)$ of them fed for $7-12$ months, $16.9 \%$ fed for $>12$ months, $12.1 \%$ fed for $4-6$ months and $8.9 \%$ fed for $<4$ months (Table 3 ).

Out of children who have got breast milk, $86.3 \%$ of them have started additional food other than breast milk. Most of them started before the age of 6 months which accounts 65.4, 28.1\% started at the age of 6 months, 5.6\% started between the age of 7-12 months and $0.9 \%$ started after 12 months old (Figure 4). 
Table 3: Duration of breast feeding among children admitted with SAM to AA governmental hospitals, 2014.

\begin{tabular}{|l|c|c|}
\hline Age & Frequency Percent \\
\hline$<4$ months & 11 & 8.9 \\
\hline $4-6$ months & 15 & 12.1 \\
\hline $7-12$ months & 77 & 62.1 \\
\hline$>12$ months & 21 & 16.9 \\
\hline Total & 124 & 100.0 \\
\hline
\end{tabular}

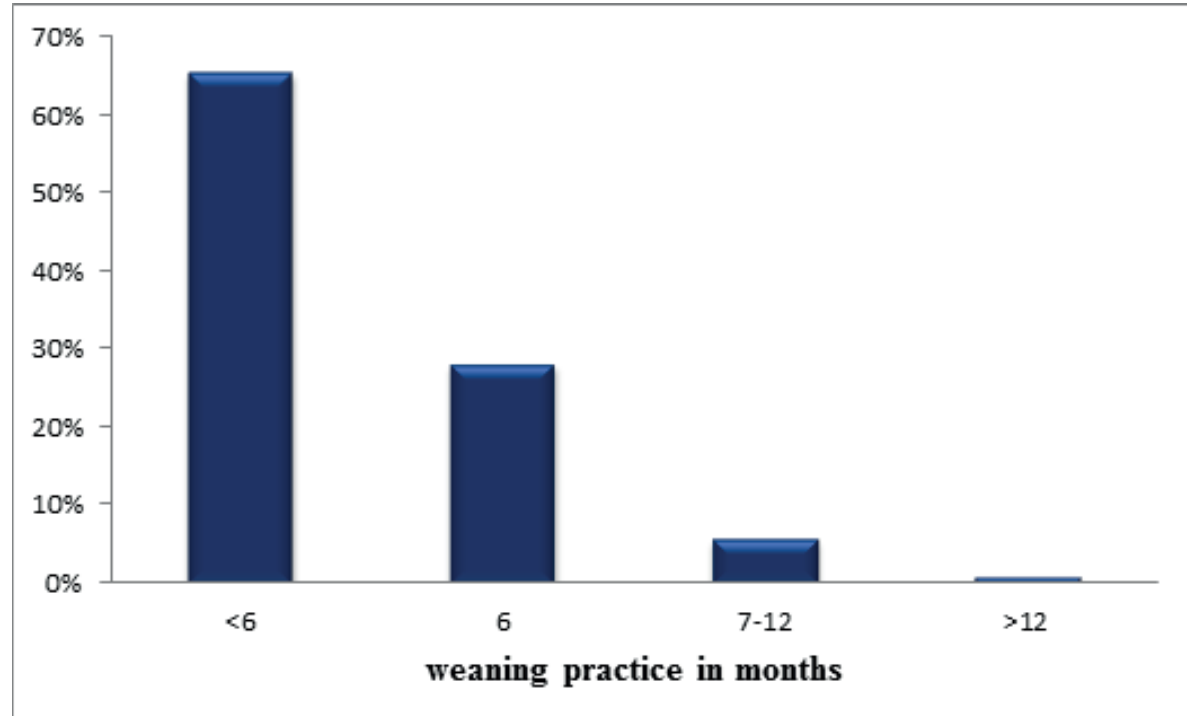

Figure 4: Weaning practice among children admitted with SAM to AA governmental hospitals, 2014.

Out of one hundred thirty four children who are currently on feeding other than breast milk and/or breast milk, $73.1 \%$ are fed by mothers or fathers, $14.9 \%$ are fed by siblings and $12.0 \%$ are fed by others like grandmother. Regarding the means of feeding foods other than breast milk, $85.8 \%$ are used bottle feeding, $10.5 \%$ are used cup and $3.7 \%$ are used spoon to feed the child (Figure 5).

\subsection{Risk factors associated with marasmus among children admitted with SAM to AA public hospitals}

From the table of association below, 55 of children 11 months and younger were marasmic. These age group s 4.37 times high risk to be affected by marasmus and has statistically significant association at $(\mathrm{COR}=4.37,95 \% \mathrm{CI}, 1.45-13.15)$. Further adjustment for other variables by multinomial logistic regression again shows that these age group is 5.97 times high risk to be affected by the case which indicate stronger association between these variables and statistically significant association at (AOR $=5.97,95 \% \mathrm{CI}, 1.8-20)$ (Table 4).

Regarding the sex, the risks of male children being marasmic relative to female children were high: 1.99 times of female children and has statistically significant association at (COR $=1.99$, 95\% CI, 1.01-3.93); and adjustment with other variables by multinomial logistic regression indicates 2.28 times high risk male children affected than female children and has statistically significant association at $(\mathrm{AOR}=2.28,95 \% \mathrm{CI}, 1.1-4.9)$ (Table 4). 


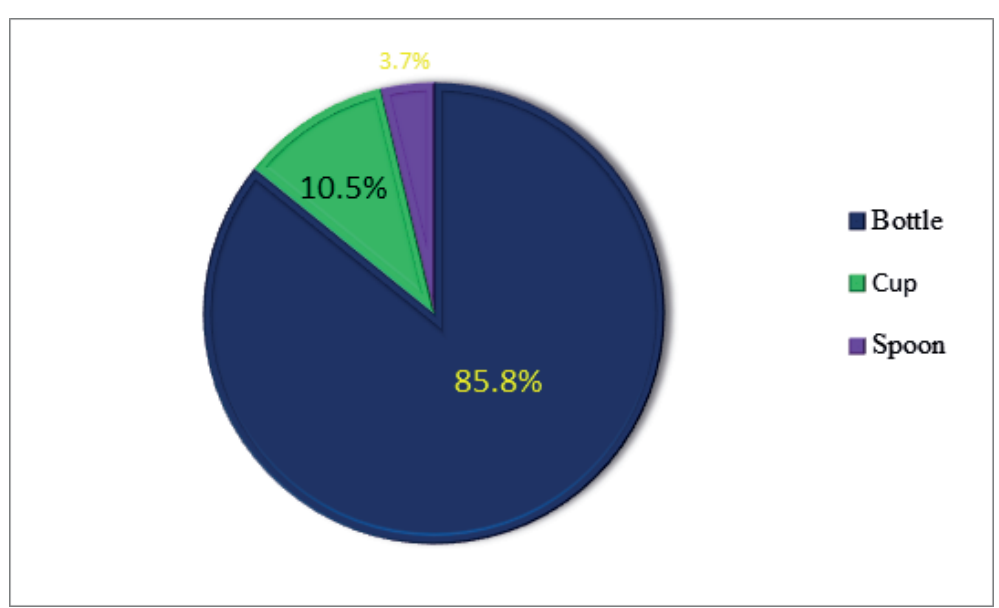

Figure 5: Means of feeding foods other than breast milk among children admitted with SAM to AA governmental hospitals, 2014.

When concerning maternal education, children from illiterate mothers were 5.04 times affected by marasmus and has statistically significant association at (COR $=5.04,95 \% \mathrm{CI}$, 1.09-234). Further adjustment also shows greater association and significance (AOR $=2.46$, 95\% CI, 1.4 - 42.4) (Table 4).

Children of governmental employee mother were 1.15 times affected by marasmus form of SAM and has statistically significant association at (COR $=1.1595 \% \mathrm{CI}, 1.12-9.89)$; then further adjustment also shows more strength and significant association at (AOR $=2.29,95 \%$ CI, 1.4 - 3.86) (Table 4).

\section{Discussion}

According to nutrition baseline survey report for the national nutrition program of Ethiopia, $12 \%$ of children aged 6 to 59 months were wasted and three percent of them were severely wasted [16]. Many studies conducted in different countries justified that maternal literacy, family income; family size, previous illness and feeding practice are the factors either directly or indirectly affecting child nutritional status. Therefore, conducting this study is mandatory to dig out which one of this factor contributes to the occurrence of severe acute malnutrition among the study subjects.

Educational level of mother is important because educated mothers are more knowledgeable about their children's health and nutrition. They can make better use of health services, provide better care, have better hygienic practices and also have higher status in the family [26]. However, majority of the study subjects' mothers have various educational level; $17.2 \%$ of them have no formal education which significantly affects nutritional status of the child among the study subjects.

Similarly, the studies conducted in Kenya in 2009/10 [27], in Nigeria [5], in Uganda [28], a cross country analysis from 63 countries [29], and Ethiopian DHS 2011 found that mother's education was strongly associated with child malnutrition [28]. 
Table 4: Risk factors associated with marasmus among children admitted with SAM to AA public hospitals, 2014.

\begin{tabular}{|c|c|c|c|c|c|c|}
\hline \multirow[t]{2}{*}{ Variables } & \multicolumn{6}{|l|}{ Marasmus } \\
\hline & Yes $\%$ & No $\%$ & p-value & $\operatorname{COR}(95 \% \mathrm{CI})$ & $\mathrm{p}$-value & $\mathrm{AOR}(95 \% \mathrm{CI})$ \\
\hline \multicolumn{7}{|c|}{ Age of child (months) } \\
\hline $0-11$ & $55(75.3)$ & $18(24.7)$ & 0.009 & $4.37(1.45-13.15)^{*}$ & 0.004 & $5.97(1.8-20)^{* *}$ \\
\hline $12-23$ & $35(57.4)$ & $26(42.6)$ & 0.24 & & & \\
\hline $24-59$ & $7(41.2)$ & $10(58.8)$ & & $1.92(0.65-5.72)$ & & \\
\hline \multicolumn{7}{|l|}{ Sex } \\
\hline Male & $63(70.8)$ & $26(29.2)$ & 0.046 & $1.99(1.01-3.93)^{*}$ & 0.035 & $2.28(1.1-4.9)^{* *}$ \\
\hline Female & $34(54.8)$ & $28(45.2)$ & & & & \\
\hline \multicolumn{7}{|c|}{ Age of mother (yrs) } \\
\hline $20-24$ & $22(71.0)$ & $9(29.0)$ & 0.447 & $1.45(0.56-3.79)$ & & \\
\hline $25-29$ & $43(62.3)$ & $26(37.7)$ & & $0.98(0.46-2.07)$ & & \\
\hline $30+$ & $32(62.7)$ & $19(37.3)$ & & & & \\
\hline \multicolumn{7}{|l|}{ Mother Education } \\
\hline Illiterate & $21(80.8)$ & $5(19.2)$ & 0.039 & $5.04(1.09-23.4)^{*}$ & 0.028 & $2.46(1.4-42.4)^{* *}$ \\
\hline Can read \& write & $19(65.5)$ & $10(34.5)$ & 0.253 & $2.28(0.56-9.36)$ & & \\
\hline Grade $1-8$ & $33(57.9)$ & $24(42.1)$ & 0.450 & $1.65(0.45-6.04)$ & & \\
\hline Grade 9-12 & 19(67.9) & $9(32.1)$ & 0.202 & $2.53(0.61-10.56)$ & & \\
\hline College/University & $5(45.5)$ & $6(54.5)$ & & & & \\
\hline \multicolumn{7}{|l|}{ Father Education } \\
\hline Illiterate & $4(57.1)$ & $3(42.9)$ & 0.650 & $0.67(0.12-3.84)$ & & \\
\hline Can read \& write & $9(90.0)$ & $1(10.0)$ & 0.191 & $4.5(0.47-42.97)$ & & \\
\hline Grade $1-8$ & $33(62.3)$ & $20(37.7)$ & 0.723 & $0.83(0.29-2.39)$ & & \\
\hline Grade $9-12$ & $15(48.4)$ & 16(51.6) & 0.196 & $0.47(0.15-1.48)$ & & \\
\hline College/University & $14(66.7)$ & $7(33.3)$ & & & & \\
\hline \multicolumn{7}{|c|}{ Mother occupation } \\
\hline Housewife & $27(56.2)$ & $21(43.8)$ & 0.119 & $3.86(0.71-21.09)$ & & \\
\hline Gov’t employee & $7(77.8)$ & $2(22.2)$ & 0.040 & $1.15(1.12-9.89)^{*}$ & 0.030 & $2.29(1.4-38.6)^{* *}$ \\
\hline Merchant & $16(76.2)$ & $5(23.8)$ & 0.019 & $9.6(1.45-63.5)^{*}$ & & \\
\hline Daily labor & $45(69.2)$ & $20(30.2)$ & 0.026 & $6.75(1.25-36.4)^{*}$ & & \\
\hline Private worker & $2(25.0)$ & $6(75.0)$ & & & & \\
\hline \multicolumn{7}{|l|}{ Father occupation } \\
\hline Gov’t employee & $9(56.2)$ & $7(43.8)$ & 0.821 & $0.86(0.23-3.25)$ & & \\
\hline Merchant & $20(76.9)$ & $6(23.1)$ & 0.221 & $2.22(0.62-7.97)$ & & \\
\hline Daily labor & $34(56.7)$ & $26(43.3)$ & 0.794 & $0.87(0.31-2.44)$ & & \\
\hline Private worker & $12(60.0)$ & $8(40.0)$ & & & & \\
\hline \multicolumn{7}{|l|}{ Marital status } \\
\hline Single & $3(75.0)$ & $1(25.0)$ & 0.287 & $6(0.22-162.53)$ & & \\
\hline Married & $75(61.5)$ & $47(38.5)$ & 0.349 & $3.2(0.28-36.18)$ & & \\
\hline Divorced & $18(81.8)$ & $4(18.2)$ & 0.102 & $9(0.65-125.32)$ & & \\
\hline Widowed & $1(33.3)$ & $2(66.7)$ & & & & \\
\hline
\end{tabular}




\begin{tabular}{|c|c|c|c|c|}
\hline Variables & Marasmus & & & \\
\hline Monthly incon & & & & \\
\hline$<500$ birr & $18(62.1)$ & 11(37.9) & 0.726 & $1.23(0.91-3.85)$ \\
\hline 500-1000 birr & $38(64.4)$ & 21(35.6) & 0.556 & $1.36(0.49-3.75)$ \\
\hline 1100-1500 birr & $13(65.0)$ & $7(35.0)$ & 0.607 & $1.39(0.39-4.92)$ \\
\hline $1600-2000$ birr & $16(72.7)$ & $6(27.3)$ & 0.287 & $2(0.56-7.16)$ \\
\hline$>2000$ birr & $12(57.1)$ & $9(42.9)$ & & \\
\hline Family size & & & & \\
\hline$<4$ & $28(63.6)$ & $16(36.4)$ & 0.921 & $0.96(0.46-2.0)$ \\
\hline$>=4$ & $69(64.5)$ & $38(35.5)$ & & \\
\hline Previous illnes & & & & \\
\hline Yes & $34(54.0)$ & $29(46.0)$ & 0.027 & $0.47(0.24-0.92)^{*}$ \\
\hline No & $63(71.6)$ & $25(28.4)$ & & \\
\hline Severe vomiti & & & & \\
\hline Yes & $17(48.6)$ & $18(51.4)$ & 0.282 & $0.58(0.21-1.57)$ \\
\hline No & $18(62.1)$ & 11(37.9) & & \\
\hline Fever & & & & \\
\hline Yes & $27(60.0)$ & $18(40.0)$ & 0.192 & $2.1(0.69-6.13)$ \\
\hline No & $8(42.1)$ & 11(57.9) & & \\
\hline Diarrhea & & & & \\
\hline Yes & $22(53.7)$ & $19(46.3)$ & 0.825 & $0.89(0.32-2.49)$ \\
\hline No & $13(56.5)$ & $10(43.5)$ & & \\
\hline Pneumonia & & & & \\
\hline Yes & $12(70.6)$ & $5(29.4)$ & 0.130 & $2.5(0.76-8.23)$ \\
\hline No & $23(48.9)$ & $24(51.1)$ & & \\
\hline Chronic illness & & & & \\
\hline Yes & $12(44.4)$ & $15(55.6)$ & 0.191 & $0.51(0.19-1.40)$ \\
\hline No & $22(61.1)$ & 14(38.9) & & \\
\hline Breast feed & & & & \\
\hline Yes & $78(63.4)$ & 45(36.6) & 0.658 & $0.82(0.34-1.97)$ \\
\hline No & 19(67.9) & $9(32.1)$ & & \\
\hline Weaning pract & & & & \\
\hline$<6$ months & $53(69.7)$ & $23(30.3)$ & 0.157 & $1.62(0.83-3.18)$ \\
\hline 6 months & $24(52.2)$ & $22(47.8)$ & 0.042 & $0.48(0.24-0.98)^{*}$ \\
\hline 7-12 months & $5(50.0)$ & $5(50.0)$ & & \\
\hline$>12$ months & $1(100.0)$ & & & \\
\hline Means of feed & & & & \\
\hline Bottle & $74(64.3)$ & $41(35.5)$ & 0.247 & $1.8(0.66-4.9)$ \\
\hline Cup & $7(50.0)$ & $7(50.0)$ & & \\
\hline Spoon & $3(50.0)$ & $2(50.0)$ & & \\
\hline
\end{tabular}

Note: *significant association by binary logistic regression

**Significant association by multinomial logistic regression 
Being age 11 months or younger increased the risk of severe acute malnutrition as shown strong association in this study. The reason behind may be inappropriate weaning practice as indicated in this study most of the study subjects abruptly weaned which increases risk of different diseases which in turn affects nutritional status of the child.

Regarding maternal occupation, children from governmental employee mothers were highly affected because these children may be fed by servants, elder siblings and others who may not care for the child as mother.

Male children were affected than female children in this study. But reason why being male child predispose to the case is unclear which needs further investigation.

In this study, many of the study subjects were reported more than one past illness they have been experienced a month prior to the study. But there is no significant association shown with severe acute malnutrition in case of this study. The reason behind is the difference of study subjects, severity of the case and duration of the diseases they have been experienced. The study conducted in Nigeria indicated that the risk of severe acute malnutrition among children who have experienced malaria, diarrhea and respiratory diseases was higher [30].

Even though, most of the children participated in this study were breastfed, $65.4 \%$ of them have been started complementary feeding before the age of six months. According to WHO recommendation the child should be exclusively feed breast milk for the first six months of life. This helps the child to achieve optimal growth, development and health [27]. But most of the study subjects of this study did not practice in same way. They put their child on complementary feeding earlier than six months. The findings of different studies conducted in different countries indicate the same results in relation to the risk of early weaning practice. The study conducted in China showed that introduction of complementary feeding before six months of life increased the prevalence of pneumonia and diarrheal diseases which in turn interrupt nutritional status of the child [23]. Similarly, the study conducted in Kenya showed that the risk of SAM increased among the children abruptly weaned [24].

Regarding means of feeding foods other than breast milk, however, there is no significant association between severe acute malnutrition and means of feeding in this study; most of the study subjects' family used bottle feeding which increases the risk of malnutrition and other diseases. Many studies showed that bottle-feeding should be discouraged at any age because it is usually associated with increased risk of illness, and especially diarrheal disease, because of the hygienic problem which is difficulty in sterilizing the nipples properly. It also shortens the period of postpartum amenorrhea and increases the risk of pregnancy [15, 30].

\section{Conclusion}

Regarding breast feeding practice, most of the study subjects have fed breast milk since their birth. Although, most of the variables analyzed in this study did not show statistically significant association with the outcome variable, maternal education, maternal occupation, sex of the child being male and age of the child younger than 11 months have strong and statistically significant association with child severe acute malnutrition. 


\section{Abbreviations}

AIDS: Acquired Immunodeficiency Syndrome

HIV: Human Immunodeficiency Virus

LMIC: Low and Middle Income Countries

MDG: Millennium Development Goal

\section{Competing Interests}

The authors declare that they have no competing interests.

\section{Acknowledgement}

We would like to express our sincere thanks to Addis Ababa University College of Health sciences. We also want to thanks Addis Ababa City Administration Health Office and staffs, heath facilities managers and staffs, supervisors, data collectors and participants of the study. Finally, we would like to thanks families of the Authors.

\section{Authors' Contribution}

Gebre Gelana, Berhanu Dessalegn, Serawit Lakew, and Girma Alemu

GG Developed design, performed statistical analysis and developed the sequence of manuscript alignment and prepared the manuscript draft. BD revised the manuscript, helped in design development and statistical performance. GA participated in sequence of manuscript alignment and revised the manuscript. All Authors read and approved the final manuscript.

\section{Authors' Information}

GG: Lecturer (MSc), Department of Nursing, Arba Minch University, Arba Minch, South West Ethiopia.

BD: Lecturer (MSc), Department of Nursing and Midwifery, Addis Ababa University, Addis Ababa, Ethiopia.

GA: MSc Candidate at Pan Africa University of Life and Earth Science Institute, Ibadan, Nigeria.

\section{References}

[1] HC W. Food, Agriculture, and Disease, "Principle of Medicine in Africa," Eldryd Parry, Ed., pp. 46-103, ELBS edition, 1984.

[2] M. Chopra, E. Mason, J. Borrazzo et al., "Ending of preventable deaths from pneumonia and diarrhoea: An achievable goal," The Lancet, vol. 381, no. 9876, pp. 1499-1506, 2013.

[3] L. C. Smith, U. Ramakrishnan, A. Ndiaye, L. Haddad, and R. Martorell, "The importance of women's status for child nutrition in developing countries," Research Report of the International Food Policy Research Institute, no. 131, pp. 1-164, 2003. 
[4] Mu'awiyyah Babale Sufiyan SSB and Ahmad Ayuba Umar, Annals of Nigerian Medicine, vol. 6, no. 2, pp. 61-64, 2012.

[5] J. Haidar, G. Abate, W. Kogi-Makau, and P. Sorensen, "Risk factors for child under-nutrition with a human rights edge in rural villages of North Wollo, Ethiopia," East African Medical Journal, vol. 82, no. 12, pp. 625-630, 2005.

[6] S. I. Ighogboja, "Some factors contributing to protein-energy malnutrition in the middle belt of Nigeria," East African Medical Journal, vol. 69, no. 10, pp. 566-571, 1992.

[7] J. K. Kikafunda, A. F. Walker, D. Collett, and J. K. Tumwine, "Risk factors for early childhood malnutrition in Uganda," Pediatrics, vol. 102, no. 4, p. E45, 1998.

[8] L. Jeyaseelan and M. Lakshman, "Risk factors for malnutrition in south Indian children," Journal of Biosocial Science, vol. 29, no. 1, pp. 93-100, 1997.

[9] F. J. Henry, A. Briend, V. Fauveau, S. R. A. Huttl, M. Yunus, and J. Chakraborty, "Risk factors for clinical marasmus: A case-control study of bangladeshi children," International Journal of Epidemiology, vol. 22, no. 2, pp. 278-283, 1993.

[10] K. Sakisaka, S. Wakai, C. Kuroiwa et al., "Nutritional status and associated factors in children aged 0-23 months in Granada, Nicaragua," Public Health, vol. 120, no. 5, pp. 400-411, 2006.

[11] M. Aminul Islam, M. Mujibur Rahman, and D. Mahalanabis, "Maternal and socioeconomic factors and the risk of severe malnutrition in a child: A case-control study," European Journal of Clinical Nutrition, vol. 48, no. 6 , pp. 416-424, 1994.

[12] T. Getaneh, A. Assefa, and Z. Tadesse, "Protein-energy malnutrition in urban children: Prevalence and determinants," Ethiopian Medical Journal, vol. 36, no. 3, pp. 153-166, 1998.

[13] S. I. Odunayo and A. O. Oyewole, "Risk factors for malnutrition among rural Nigerian children," Asia Pacific Journal of Clinical Nutrition, vol. 15, no. 4, pp. 491-495, 2006.

[14] Solomon Amsalu and Zemene Tigabu, "Risk factors for severe acute malnutrition in children under the age of five: A case-control study," Ethiopian Journal of Health Development, vol. 22, no. 1, pp. 21-25, 2008.

[15] Nutrition baseline survey report for the National Nutrition Program of Ethiopia, Ethiopian Health and Nutrition Research Institute, 2009/10.

[16] "Ethiopia National Nutrition Strategy Review and Analysis of Progress and Gaps: One Year On May," 2009.

[17] CSA. [Ethiopia] and ORC Macro USA, "Ethiopia Demographic and Health Survey 2011," Central Statistical Agency, Addis Ababa, Ethiopia.

[18] J. Haidar, G. Abate, W. Kogi-Makau, and P. Sorensen, "Risk factors for child under-nutrition with a human rights edge in rural villages of North Wollo, Ethiopia," East African Medical Journal, vol. 82, no. 12, pp. 625-630, 2005.

[19] S. I. Odunayo and A. O. Oyewole, "Risk factors for malnutrition among rural Nigerian children," Asia Pacific Journal of Clinical Nutrition, vol. 15, no. 4, pp. 491-495, 2006.

[20] B. Jamro, A. A. Junejo, S. Lal, G. R. Bouk, and S. Jamro, "Risk Factors for Severe Acute Malnutrition in Children under theAge of Five Year in Sukkur," Pakistan Journal of Medical Research, vol. 51, no. 4, pp. 111-113, 2012.

[21] World Health Assembly Resolution, "Infant and young child nutrition," 2001.

[22] X. Wang, Y. Wang, and C. Kang, "Feeding practices in 105 counties of rural China," Child: Care, Health and Development, vol. 31, no. 4, pp. 417-423, 2005.

[23] E. Bloss, F. Wainaina, and R. C. Bailey, "Prevalence and predictors of underweight, stunting, and wasting among children aged 5 and under in Western Kenya," Journal of Tropical Pediatrics, vol. 50, no. 5, pp. 260-270, 2004.

[24] Central Statistical Agency [Ethiopia] and ORC Macro [USA], "Ethiopia Demographic and Health Survey 2011," Central Statistical Agency, Addis Ababa, Ethiopia, 2014.

[25] A. S. Ahmed, T. Ahmed, S. K. Roy, N. Alam, and M. I. Hossain, "Determinants of undernutrition in children under 2 years of age from Rural Bangladesh," Indian Pediatrics, vol. 49, no. 10, pp. 821-824, 2012.

[26] B. A. Abuya, J. Ciera, and E. Kimani-Murage, "Effect of mother's education on child's nutritional status in the slums of Nairobi," BMC Pediatrics, vol. 12, article no. 80, 2012.

[27] H. Wamani, A. N. Åstroøm, S. Peterson, J. K. Tumwine, and T. Tylleskär, "Predictors of poor anthropometric status among children under 2 years of age in rural Uganda," Public Health Nutrition, vol. 9, no. 3, pp. 320-326, 2006.

[28] Lisa C. Smith and Lawrence James Haddad, "Explaining child malnutrition in developing countries. A crosscountry analysis," International Food Policy Research Institute, Washington, D.C.

[29] FMOH, "National Child health policy. Nigeria: Federal Ministry of Health (FMOH)," 2006.

[30] Central Statistical Agency [Ethiopia] and ORC Macro, "Ethiopia Demographic and Health Survey 2005," Central Statistical Agency and ORC Macro, Addis Ababa, Ethiopia, and Calverton, Maryland, USA, 2006. 